\title{
Ступени коэффициента прохождения через одномерный барьер в высокочастотном поле
}

\author{
О.А. Ткаченко ${ }^{1)}$, В.А. Ткаченко ${ }^{1,2)}$, Д.Г.Бакшеев ${ }^{2}$ \\ ${ }^{1}$ Институт физики полупроводников им. А.В.Ржанова СО РАН, Новосибирск, 630090, Лаврентьева \\ 13, тел:+7 (383) 333-10-80, факс:+7 (383)333-10-80, эл.nочта: vtkach@isp.nsc.ru \\ ${ }^{2}$ Новосибирский государственный университет, Новосибирск, 630090
}

DOI 10.34077/RCSP2019-135

В работах [1,2] предсказаны ступени для усредненного по времени коэффициента прохождения $\mathrm{D}(\mathrm{E})$ через одномерный барьер колеблющейся высоты $\mathrm{U}(\mathrm{x}, \mathrm{t})=[\mathrm{V}+\mathrm{A} \cos (\omega \mathrm{t})] / \mathrm{ch}^{2}(\mathrm{x} / \mathrm{W})$, где $\mathrm{E}$ начальная энергия частицы, падающей на барьер, и амплитуда высокочастотного поля $\mathrm{A} \sim \mathrm{V}-\mathrm{E} \mid<<\mathrm{V}$. B связи с недавним экспериментом (ссылки в $[1,2])$ численно изучен случай $\mathrm{V}=30$ мэB, $\mathrm{W} \approx 100$ нм, $\mathrm{m}^{*}=0.07 \mathrm{~m}_{\mathrm{e}}$, который моделирует туннельный точечный контакт в двумерном электронном газе структуры GaAs/AlGaAs. Расчеты для ћ производной $\left.\mathrm{D}^{\prime}(\mathrm{E})\right)$ (рис.1,2). На терагерцовых частотах, когда $\omega^{-1}$ меньше времени туннелирования $\tau=\pi \mathrm{W}\left(\mathrm{m}^{*} / 2 \mathrm{~V}\right)^{1 / 2}$, положение ступеней дается простой формулой $|\mathrm{E}-\mathrm{V}|=\mathrm{n} \hbar \omega(\mathrm{n}=1,2,3)$ и не зависит от $\mathrm{A}$ (рис.1) [1]. В данном случае $\hbar / \tau \approx 1$ мэВ. При $\omega \tau \approx 1$ эти фотонные ступени размываются, но когда $\omega \tau<<1$ (f $<10$ ГГц) появляются две ступени в $\mathrm{D}(\mathrm{E})$ с положением $|\mathrm{E}-\mathrm{V}| \approx \mathrm{A}$, которое не зависит от частоты f (рис.2) [2]. Эти эффекты, полученные решением нестационарного уравнения Шредингера, предлагается обнаружить экспериментально в недавно изготовленных наноструктурах.
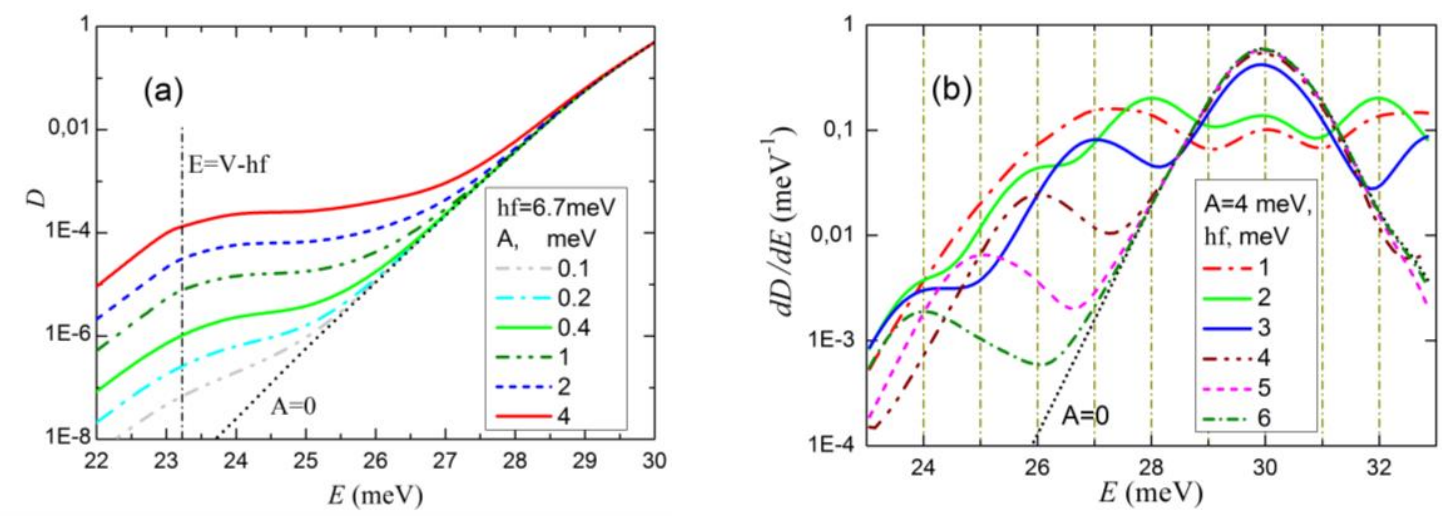

Рис.1. Ступени $\mathrm{D}(\mathrm{E})$ при $\mathrm{f}=1.63$ ТГц (a), пики $\mathrm{D}^{\prime}(\mathrm{E})$ при $\mathrm{A}=4$ мэВ и разных hf (b).
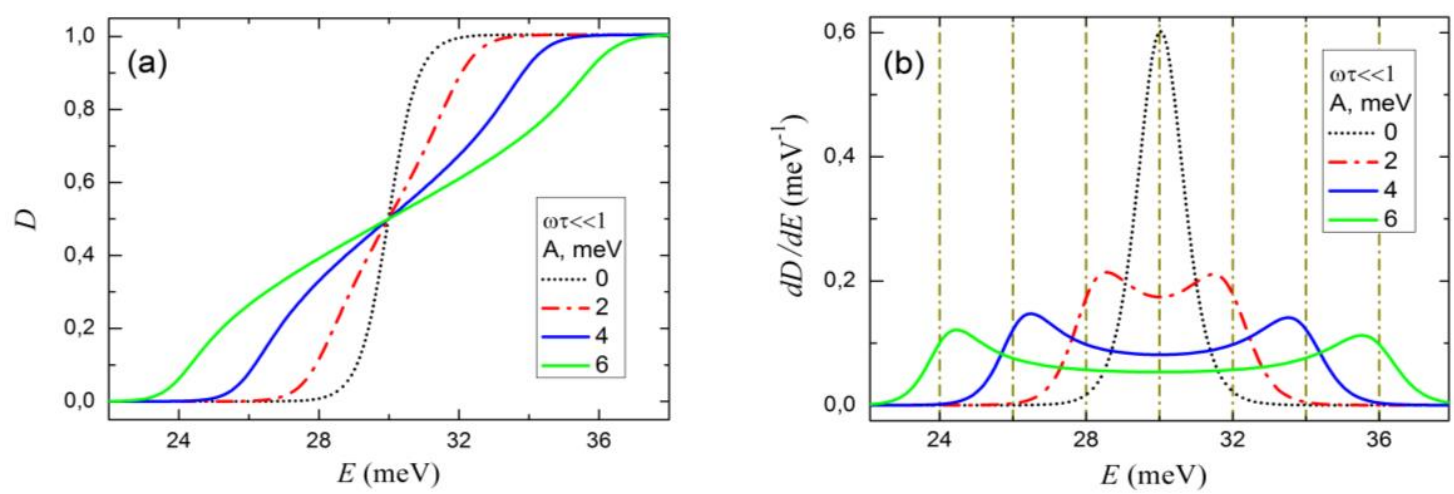

Рис.2. Ступени $\mathrm{D}(\mathrm{E})$ в низкочастотном пределе (a) и пики $\mathrm{D}^{\prime}(\mathrm{E})$ при разных $\mathrm{A}(\mathrm{b})$.

\section{Лumepamypa}

[1] O.A. Tkachenko, V.A. Tkachenko, D.G. Baksheev, Z.D.Kvon//JETP letters. 2018. V.108. P. 396-401.

[2] О.А. Ткаченко, В.А. Ткаченко, Д.Г. Бакшеев//Сибирский физический журнал. 2018. Т. 13, № 4. С. 74-90. 